\title{
Ankilozan Spondilitli Bireylerde Eklem ve Enerji Koruma Eğitiminin Ağrı, Yorgunluk ve Aktivite Performansına Etkisinin İncelenmesi
}

\author{
Investigation of the Effects of Energy Conservation and Joint Protection Education on \\ Pain, Fatigue and Activity Performance in Individuals with Ankylosing Spondylitis
}

\section{Elif Nur KASKIR ${ }^{1}$, Gamze EKici²}

${ }^{1}$ Erg., Hacettepe Üniversitesi, Sağlık Bilimleri Fakültesi, Ergoterapi Bölümü, Ankara

${ }^{2}$ Doç. Dr., Hacettepe Üniversitesi, Sağlık Bilimleri Fakültesi, Ergoterapi Bölümü, Ankara

\section{öz}

Amaç: Bu çalışma ankilozan spondilitli (AS) bireylerde eklem ve enerji koruma eğitiminin ağrı, yorgunluk ve aktivite performansı üzerindeki etkinliğini değerlendirmek amacıyla yapıldı. Gereç ve Yöntem: Çalışmaya AS tanısı almış ve herhangi bir nörolojik hastalığı olmayan 5 birey dahil edildi. Bireylerin sosyo-demografik bilgileri kaydedildi. Çalışma kapsamında yorgunluk için görsel benzerlik skalası; aktivite performansı Kanada Aktivite Performans Ölçümü (KAPÖ) ve ağrı görsel analog skala (GAS) kullanılarak değerlendirildi. Bireylere haftada bir gün 40 dk olmak üzere 4 hafta boyunca toplamda 160 dk'lık eklem ve enerji koruma eğitimi verildi. Sonuçlar: Bireylerin müdahale öncesi ve sonrası ağrı ve yorgunluk değerlendirme sonuçların istatiksel olarak anlamlı bulunmasa ( $p>0.05$ ) da ağrı ve yorgunluk şiddetlerinde düşüş; enerji düzeyi ortalamasında artış olduğu görülmüştür. Bireylerin müdahale öncesi ve sonrasında değerlendirilen aktivite performansları $(p=0.043)$ ve performans memnuniyetlerinde $(p=0.043)$ ise anlamlı bir artış olduğu saptanmıştır. Tartışma: AS'li bireylerde eklem ve enerji koruma eğitimi aktivite performansı ve memnuniyetini arttırmıştır. Çalışmamızın sonucunda eklem ve enerji koruma eğitiminin AS'li bireylerin ağrı şiddeti, yorgunluk şiddeti ve aktivite performansı üzerinde olumlu etkisi olması nedeniyle rehabilitasyon programlarına bu eğitimin eklenmesinin iyi olabileceği görüşüne varıldı. Bu sonuçlara rağmen, geniş grupların dahil edildiği ileri çalışmalara intiyaç olduğu düşünülmektedir.

Anahtar Kelimeler: Ağrı; Yorgunluk; Ankilozan spondilit

\section{A B S T R AC T}

Purpose: This research was planned to determine the effectiveness of energy conservation and joint protection training on pain, fatigue and occupational performance in individuals with ankylosing spondylitis (AS). Material and Methods: Five individuals with AS without any other disease were participated to the study. For fatigue the scale to assess fatigue also Canadian Occupational Performance Measure (COPM) was used for determining of occupational performance, pain was assessed by visual analogue scale (VAS). Energy conservation and joint protection education were given totally 160 minutes during 4 weeks for individuals. Results: Both pre and post intervention pain and fatigue results of individuals were not statistically significant $(p>0.05)$, however the pain and fatigue severity which they have expressed decreased and average of energy level increased. There is a significant increase in activity performance $(p=0.043)$ and satisfaction $(p=0.043)$ of individuals after the treatment. Conclusion: Energy conservation and joint protection education has increased the activity performance and satisfaction in individuals with AS. As a result of this study, energy conservation and joint protection education were considered to have a positive impact for pain, fatigue and activity performance in individuals with AS and this training should be added to the rehabilitation programs. According to these results further studies are needed which includes larger groups

KeyWords: Pain; Fatigue; Ankylosing spondylitis 
A nkilozan Spondilit (AS), özellikle aksiyal iskeleti etkileyen kronik, inflamatuvar bir hastalıktır (Jeong, Eun, Kim ve ark, 2016). Türk topIumuna göre standardize edilmiş AS prevelansı \% 0.49 olarak bulunmuştur (Önen, Akar, Birlik ve ark, 2008). AS'de özellikle ağrı ve tutukluk birincil semptom olarak söylense de yorgunluğun da önemli bir bulgu olduğu belirtilmektedir (Ward, 1999). Değerlendirmeler, AS'li bireylerin \% 66'sının yorgunluktan etkilendiğini göstermektedir (Haywood, Packham, Jordan, 2013). AS'de görülen ağrı, yorgunluk, uyku bozukluğu gibi şikayetler bireylerin günlük yaşamını zorlaştırmaktadır (Karkucak, Özden, Çapkın ve ark, 2008). Ağrının, aile sorumluluklarını yerine getirmede ve sosyal ilişkilerde limitasyon yarattığı ayrıca iş aktivitelerinde problemlere neden olduğu belirtilmektedir (Bagcivan, Cinar, Cinar ve ark, 2014).

Kanada Aktivite Performans Modeli'ne göre bireylerin aktiviteleri kendine bakım, üretkenlik ve serbest zaman aktivitelerinden meydana gelmektedir. Bireyi tanımlayan bu aktiviteler, roller; bireyin kendisi ve aktiviteleri gerçekleştirdiği çevre arasındaki kesişime aktivite performansı denir. Aktivite performansı hastalık, etkilenim gibi kişisel faktörlerle ilişkilidir (Karayazgan, 2013; Baum, Law, 1997). AS'de görülen aksiyal iskeletteki dejenerasyonlar, ağrı ve yorgunluk bireylerin kendine bakım, serbest zaman ve üretici aktivitelerinde limitasyona neden olmaktadır (Spadaro, Massimiani, Ceccarelli ve ark, 2008).

AS'ye yönelik rehabilitasyon yaklaşımlarında pek çok müdahale yönteminden bahsedilmektedir (Clark, 2000). Özellikle fiziksel olarak aktivite düzeyinin artırılması ve gevşeme egzersizlerinin yararlı etkisinden bahsedilmektedir (Fernández, Sanchez, Lopez ve ark., 2015). Ergoterapi müdahaleleri kapsamında splintleme, yardımcı cihaz kullanımı, iş ve serbest zaman aktiviteleri danışmanlığı, cinsel danışmanlık, ağrı ve stres yönetimi, gevşeme, eklem koruma ve yorgunluk eğitimleri uygulanmaktadır. Ergoterapi müdahalelerinin genel amacı bireyin günlük yaşamdaki aktivite performansını geliştirmek, yaşam tarzında başarılı adaptasyonlar yapmak, fonksiyon kaybını önlemek, psikolojik durumu korumak ya da iyileştirmektir (Spadaro, Massimiani, Ceccarelli ve ark., 2008). Ergoterapi bilimi kapsamında uygulanan müdahalelerden eklem ve enerji koruma prensipleri; yorgunluğu en aza indirmeyi, eklemler üzerindeki stresi ve ağrıyı azaltmayı, günlük yaşam aktivitelerindeki performansı arttırmayı hedeflemektedir (Clark, 2000).

Yukarıda bahsi geçen ve aktiviteyi artırmanın değerini ortaya koyan (Tyrrell, ve Redshaw, 2016; Fernández, Sanchez, Lopez ve ark., 2015) çalışmalarda aktivite yapılırken ağrı ve yorgunlukla nasıl baş edileceğine dair bilginin eksik olduğu görülmüştür. Ayrıca, yapılan incelemelerde AS'li bireylerde eklem ve enerji koruma eğitiminin etkinliğini değerlendiren bir çalışmaya rastlanmamıştır. Bu nedenle, bu çalışma AS'li bireylerde eklem ve enerji koruma eğitiminin ağrı, yorgunluk ve aktivite performansı üzerindeki etkinliğini incelemek amacıyla planlanmıştır.

\section{GEREÇ VE YÖNTEM}

Çalışmaya AS tanısı almış ve herhangi başka bir fiziksel ya da psikolojik hastalığı olmayan 5 birey dahil edilmiştir. Çalışma kapsamında Ocak-Mart 2016 tarihleri arasında bireylere eklem ve enerji koruma eğitimi verilmiş, müdahale öncesi ve sonrası olmak üzere 2 kere değerlendirme yapılmıştır.

Katılımcılara çalışma hakkında bilgi verilip gönüllü olarak kabul edenlere Helsinki bildirgesi ile birlikte çalışmanın amacını belirten bir onam formu imzalatılmıştır. Çalışmaya katılan bireylere sosyodemografik anket uygulanmıştır. Çalışma kapsamında yorgunluk için görsel benzerlik skaIası; aktivite performansı KAPÖ ve ağrı GAS kullanılarak değerlendirilmiştir.

\section{Değerlendirmeler}

Yorgunluk için Görsel Benzerlik Skalası: Yorgunluk ve enerji durumunu değerlendirir. Artritli bireylerin yorgunluğunun değerlendirildiği bir çaIışmada yorgunluk alt skalasının Cronbach alfası 0.87 , enerji alt skalasınınki ise 0.84 bulunmuştur (Ünsal, 2009). Bu skala 13 tane yorgunlukla ilgili, 5 tane enerji ile ilgili olmak üzere toplam 18 ifadeden oluşmaktadır (Lee, Hicks, Nino-Murcia, 1991). Her ifadenin altında bir ucunda en olumlu diğer ucunda en olumsuz ifadelerin bulunduğu 10 cm'lik skala bulunur. Yorgunlukla ilgili ifadelerden alınan yüksek puan, enerjiyle ilgili ifadelerden alınan düşük puan yorgunluğun şiddetini göstermektedir (Yurtsever ve Bedük, 2003). 


\begin{abstract}
Kanada Aktivite Peformans Ölçümü (KAPö): Kanada Aktivite Performans Ölçümü bireylerin kendine bakım, üretkenlik ve serbest zaman aktivitelerindeki performans problemlerini tanımlamak için kullanılan yarı yapılandırılmış bir görüşmedir. Birey bu aktivitelerin önemini 1 (hiç önemli değil) ile 10 (çok önemli) puan arasında puanlar. Bu listeden odaklanılmak istenen en önemli beş aktivite seçilir. Sonrasında seçilen en önemli aktivitelerin her biri için performans (1=hiç yapamıyorum, 10=çok iyi yapıyorum) ve bireyin bu performanstan duyduğu memnuniyet puanı (1=hiç memnun değilim, 10=çok memnunum) alınır. Toplam performans ve memnuniyet puanı bireyin aktivitelere verdiği performans ve memnuniyet puanları toplanıp aktivite sayısına bölünerek hesaplanır. COPM'ün geliştirilmesi, geçerlilik ve güvenilirlik çalışması Law ve ark. tarafından yapılmıştır (Law, Bapiste, Carswel ve ark, 2005).
\end{abstract}

Görsel Analog Skalası (GAS): Price ve ark. tarafından geliştirilen GAS ağrı şiddetinin araştırılmasında kullanılır. Skala $10 \mathrm{~cm}$ uzunluğunda

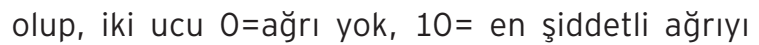
gösterecek şekilde düzenlenmiştir. Çizgi üstünde hastanın hissettiği ağrı şiddetine karşılık gelen bir noktayı belirlemesi istenir. Bildirilen değer hastanın ağrı şiddetini gösterir. (Price, McGrath, Rafii ve ark. 1983; Hawker, Mian, Kendzerska ve ark, 2011).

\section{Eklem ve Enerji Koruma Eğitimi}

Bireylere, eklem ve enerji koruma eğitim programına başlanmadan önce yukarıda belirtilen değerlendirmeler yapıımıştır. 4 hafta boyunca haftada bir gün 40 dakika olmak üzere 4 seans eğitim verilmiştir. Eklem ve enerji koruma eğitimi kapsamında;

1.hafta: Eklem ve enerji eğitiminin amaçları, temel ilkeleri, doğal spinal eğrilikler, hastalık postürü, normal postür ve bozuk postür

2.hafta: Doğru ayakta duruş, doğru oturma, doğru taşıma teknikleri, doğru postürün yararları

3.hafta: Farklı aktiviteler için postür önerileri, el için koruma yöntemleri, yorgunluğa neden olan faktörler üzerinde çalışma

4.hafta: Enerji yönetimi için temel prensipler anlatılmıştır.

\section{İstatiksel Analiz}

istatistiksel analizlerde 'SPSS 16 for Windows' istatistik programı kullanımıştır. Bireylerin sosyodemografik özellikleri, meslekleri, sigara, alkol kullanımları, hastalık süreleri, düzenli egzersiz ve ilaç kullanımları gibi tanımlayıcı verilerde uygunluğuna göre frekans ve/veya ortalama \pm standart sapma $(\mathrm{X} \pm \mathrm{SS})$ değerleri verilmiştir. Yorgunluk, ağrı, aktivite performansı için müdahale öncesi ve 4 seans sonra elde edilen veriler 'Wilcoxon Eşleştirilmiş Test' kullanılarak değerlendirilmiştir. İstatistiksel anlamlılık düzeyi $p<0.05$ olarak kabul edilmiştir.

\section{SONUÇLAR}

Dokuz kişi ile başlayan çalışmamızdan, değerlendirmeler alındıktan sonra 4 kişi ayrılmak durumunda kalmıştır. Sonuç olarak çalışmaya yaşları 23-45 arasında olan yorgunluğa neden olabilecek herhangi bir nörolojik hastalığı olmayan, AS tanısı almış 5 birey dahil edilmiştir (Tablo 1). Bireylerin müdahale öncesi ve müdahale sonrası ağrı ve yorgunluk değerlendirme sonuçlarının $p$ değeri anlamlı çıkmamasına rağmen Tablo 4'de belirtildiği gibi ifade ettikleri ağrı şiddeti ve yorgunluk şiddeti ortalamasında bir düşüş; enerji düzeyi ortalamasında artış meydana gelmiştir. Bireylerin müdahale öncesi ve sonrasında değerlendirilen aktivite performansları ve performans memnuniyetlerinde anlamlı bir artış olduğu saptanmıştır. $p$ değeri aktivite performansı ve memnuniyeti için 0.043 bulunmuştur $(p<.005)$ (Tablo 3$)$.

Çalışmaya katılan bireylerin hastalık sürelerinin ortalaması $6.6 \pm 3.286 \mathrm{yıl}$, minimummaksimum değerleri ise 4-12 yıldır. Ayrıca katılımcıların 4>ü (\% $\%$ 80) düzenli egzersiz yapmamaktadır.

\section{TARTIŞMA}

Ankilozan spondilitli bireylerde eklem ve enerji koruma eğitiminin ağrı, yorgunluk, aktivite performansı üzerindeki etkinliğini incelemeyi amaçIayan çalışmamızın bulgularına göre; aktivite performansı ve bireylerin bu performanstan duydukları memnuniyet sonuçlarının eğitim sonrası iyi olduğu görüldü.

2001'de yapılan randomize kontrollü bir çaIışmada romatoid artritli (RA) bir gruba temel hastalık eğitiminin yanı sıra 2.5 saatlik bir ek- 
Tablo 1. Sosyodemografik bilgiler ve ilaç kullanım bilgileri

\begin{tabular}{|c|c|c|}
\hline & & $n(\%)$ \\
\hline \multirow{2}{*}{ Cinsiyet } & Kadın & $2(40)$ \\
\hline & Erkek & $3(60)$ \\
\hline \multirow{2}{*}{ Eğitim } & Ortaöğretim & $1(20)$ \\
\hline & Yükseköğrenim & $4(80)$ \\
\hline \multirow{2}{*}{ Medeni Durum } & Bekar & $2(40)$ \\
\hline & Evli & $3(60)$ \\
\hline \multirow{2}{*}{ Meslek } & Çalışıyor & $4(80)$ \\
\hline & Emekli & $1(20)$ \\
\hline \multirow{2}{*}{ Sigara Kullanımı } & Hayır & $1(20)$ \\
\hline & Evet & $4(80)$ \\
\hline \multirow{2}{*}{ Alkol Kullanımı } & Hayır & $3(60)$ \\
\hline & Evet & $2(40)$ \\
\hline \multirow{3}{*}{ Düzenli ilaç kullanımı } & Hayır & $3(60)$ \\
\hline & Evet & $2(40)$ \\
\hline & Min-Max & $\mathrm{X} \pm \mathrm{SS}$ \\
\hline Yaş(Yıl) & $23-45$ & $32 \pm 9,848$ \\
\hline VKi(kg/m2) & $22,2-30$ & $26 \pm 2,821$ \\
\hline
\end{tabular}

Tablo 2. Bireylerin Kanada Aktivite Performans Ölçümü (KAPÖ) için belirledikleri aktivitelerin dağılımı

\begin{tabular}{|c|c|c|c|}
\hline \multicolumn{2}{|c|}{ PERFORMANS ALANI } & AKTIVITE & $\mathrm{n}(\%)$ \\
\hline \multirow{4}{*}{$\begin{array}{l}\text { KENDINE BAKIM } \\
\text { AKTIVITELERI }\end{array}$} & Kişisel Bakım & Ayakkabı giyme & $3(60)$ \\
\hline & $\begin{array}{c}\text { Fonksiyonel } \\
\text { Mobilite }\end{array}$ & Yataktan kalkma & $1(20)$ \\
\hline & \multirow{2}{*}{$\begin{array}{l}\text { Toplumda kendini } \\
\text { idare etme }\end{array}$} & Alışveriş & $1(20)$ \\
\hline & & Araba kullanma & $2(40)$ \\
\hline \multirow{3}{*}{$\begin{array}{l}\text { ÜRETKENLIK } \\
\text { AKTIVITELERI }\end{array}$} & $\begin{array}{c}\text { Maaşlı-Maaşsız İş } \\
\text { Aktiviteleri }\end{array}$ & - & - \\
\hline & Ev işi Yönetimi & - & - \\
\hline & $\begin{array}{l}\text { Oyun/Okul } \\
\text { aktiviteleri }\end{array}$ & - & - \\
\hline \multirow{7}{*}{$\begin{array}{l}\text { SERBEST ZAMAN } \\
\text { AKTIVITELERI }\end{array}$} & \multirow{5}{*}{ Aktif Rekreasyon } & Yürüyüş yapmak & $2(40)$ \\
\hline & & Voleybol oynamak & $2(40)$ \\
\hline & & Futbol oynamak & $2(40)$ \\
\hline & & Basketbol oynamak & $1(20)$ \\
\hline & & Avcilık & $1(20)$ \\
\hline & $\begin{array}{c}\text { Sessiz } \\
\text { Rekreasyon }\end{array}$ & - & - \\
\hline & Sosyalizasyon & - & - \\
\hline
\end{tabular}

Tablo 3. Bireylerin müdahale öncesi ve sonrası aktivite performans ve memnuniyet sonuçları

\begin{tabular}{|c|c|c|c|c|}
\hline & $\begin{array}{c}\text { Müdahale Öncesi X } \\
\mathbf{\pm S S}\end{array}$ & $\begin{array}{c}\text { Müdahale sonrası } \\
\mathbf{X} \pm \mathbf{S S}\end{array}$ & $\mathbf{z}$ & $\mathbf{p}$ \\
\hline $\begin{array}{c}\text { Aktivite } \\
\text { Performansı }\end{array}$ & $3,14 \pm 1,822$ & $5,15 \pm 1,356$ & $-2,023$ &, $043 *$ \\
\hline Memnuniyet & $1,78 \pm 2,302$ & $5,72 \pm 2,022$ & $-2,023$ &, $043 *$ \\
\hline
\end{tabular}


Tablo 4. Bireylerin müdahale öncesi ve müdahale sonrası ağrı ve yorgunluk değerlendirme sonuçları

\begin{tabular}{|c|c|c|c|c|c|}
\hline \multicolumn{2}{|c|}{} & $\begin{array}{c}\text { Müdahale Öncesi } \\
\text { X } \pm \text { SS }\end{array}$ & $\begin{array}{c}\text { Müdahale Sonrası } \\
\mathbf{X} \pm \text { SS }\end{array}$ & $\mathbf{z}$ & $\mathbf{p}$ \\
\hline \multicolumn{2}{|c|}{ Ağrı şiddeti (VAS) (0-10 cm) } & $6,3 \pm 2,991$ & $4,84 \pm 3,041$ &,- 40 &, 68 \\
\hline \multirow{2}{*}{ YigBS } & Yorgunluk (0-130 puan) & $62,1 \pm 18,536$ & $50,54 \pm 18,389$ & $-1,82$ &, 06 \\
\cline { 2 - 6 } & Enerji (0-50 puan) & $19,42 \pm 7,211$ & $33,16 \pm 17,521$ & $-1,75$ &, 08 \\
\hline
\end{tabular}

*p<,005 (YiGBS: Yorgunluk için Görsel Benzerlik Skalası)

lem koruma eğitimi verilmiştir. Eğitim sonrası 6. ay ve 12. aylarda bir değerlendirme yapılmıştır. Çalışma sonucunda katılımcıların daha iyi el fonksiyonlarından, daha az ağrı şiddeti ve sabah tutukluğundan bahsettiği ve bireylerce algılanan öz yeterlilik seviyesinin arttığı belirtilmiştir (Hammond ve Freeman, 2001). 2009 yılında yapılan bir çalışmada AS'li bireylerde eklem ve enerji koruma yöntemlerinin etkinliğinin değerlendirildiği özel bir çalışma olmadığı belirtilmiştir (Vlielan, Li, 2009). Spadaro ve arkadaşları tarafından yapılan bir çalışmada AS'li bireylere ergoterapi müdahalesi uygulanmıştır. Ergoterapi bilimi kapsamında uygulanan bu müdahaleler içerisinde eklem ve enerji koruma teknikleri eğitimi de vardır. Bu müdahaleler sonucunda ergoterapi tedavisi alan grubun kontrol grubuna göre daha iyi ağrı şiddeti ve yaşam kalitesinden bahsettiği ve bireylerin algıladıkları fonksiyonel yeterliliklerinde artış olduğu belirtilmiştir (Spadaro ve ark., 2008). Çalışmamızda bireylere 4 hafta boyunca vermiş olduğumuz toplam $160 \mathrm{dk}$ 'ık eklem ve enerji koruma eğitimi sonrasında bireylerin bahsettikleri ağrı ve yorgunluk şiddet ortalamalarında bir düşüş tespit edilmiş, fakat bu düşüş istatistiksel sonuçlara yansımamıştır. Eğitim sonrasında bireyler daha iyi aktivite performansından ve performans memnuniyetinden söz etmişlerdir. Yaptığımız çalışmayla eklem ve enerji koruma eğitiminin günlük aktivitelerdeki performansı arttırmaya yönelik uygulanması gerektiği savını kuvvetlendirdik.

Yapılan gözlemsel değerlendirmeler ve seanslar sırasında bireylerden alınan geribildirimler doğrultusunda eklem ve enerji koruma yöntemlerinin AS'li bireyler için işlevsel olduğu düşünülmektedir. Çalışmaya katılan bireylerden "Bizler ankilozan spondilit tanısı alıyoruz, ilaç veriyorlar ama kimse bize yaşamımıza nasıl devam etmemiz gerektiğini söylemiyor. Siz bunu yapıyorsunuz." "Eğitimlere başladığımızdan beri ağrılarımda azalma olduğunu hissediyorum." "Kendimi daha dinç hissediyorum." yorumları alınmıştır. Eklem ve enerji koruma eğitimin ağrı ve yorgunluk üzerinde anlamlı bir etkisinin olmamasının en önemli nedeninin çalışmadaki katııımcı sayısının azı̆̆ı olduğu düşünülmektedir.

Çalışmalar düzenli şekilde, kişiye özel planlanmış egzersizle AS'li bireyin aktivite seviyesinin artırılması sonucunda AS belirtilerinin azaldığı, bireyin genel sağlık durumunun ise iyiye gitiği yönündedir (Tyrrell, ve Redshaw, 2016; Fernández. Sanchez, Lopez ve ark., 2015). Halbuki, AS'li bireylerde görülen önemli sorunlardan ağrı ve yorgunluğun, bireyin aktivitelerini olumsuz yönde etkilemesinden dolayı mutlaka müdahale planları içine ağrı ve yorgunlukla baş etme becerilerinin geliştirilmesine yönelik yaklaşımların dahil edilmesi diğer tedavilerin yapılabilmesi ve sürdürülebilmesi açısından önemli olacaktır.

Sonuç olarak AS'li bireylere verilen eklem ve enerji koruma eğitiminin bireylerin aktivite performansları ve performanslarından duydukları memnuniyet düzeyini arttırdığı görülmüştür. Ağrı ve yorgunluk açısından anlamlı bir sonuç bulunmasa da bireylerin ifadelerine ve ortalama puanIarın düşüşüne bakıldığında eklem ve enerji koruma eğitiminin AS'li bireylerde ağrı ve yorgunluğa da olumlu etkisi olduğundan söz edilebilir. Çalışma AS'li bireylerin rehabilitasyon programı içerisinde eklem ve enerji koruma teknikleri eğitiminin de yer alması gerektiğini göstermiştir. Tüm bunlara rağmen, daha yüksek katıımcı sayısı ve kontrol 
grubunun da olduğu kanıta dayalı sonuçların elde edilebileceği ileri çalışmalara intiyaç olduğu düşünülmektedir.

\section{KAYNAKLAR}

Bagcivan, G., Cinar, F. I., Cinar, M., Oflaz, F., Uzun, S., \& Pay, S. (2016). Living in pain with ankylosing spondylitis: a qualitative study. Contemp Nurse, 51(2-3), 135-147.

Baum, C. M., \& Law, M. (1997). Occupational therapy practice: Focusing on occupational performance. $A m$ J Occup Ther, 51(4), 277-288.

Clark, B. M. (2000). Rheumatology: 9. Physical and occupational therapy in the management of arthritis. CMAJ, 163(8), 999-1005.

Fernández, G. R., Sánchez, S. L. C., López, R. M. M., \& Sánchez, G.G. (2015). Effects of an exercise and relaxation aquatic program in patients with spondyloarthritis: A randomized trial. Med Clin (Barc), 145(9), 380-384.

Hammond, A., \& Freeman, K. (2001). One-year outcomes of a randomized controlled trial of an educationalbehavioural joint protection programme for people with rheumatoid arthritis. Rheumatology, 40(9), 1044-1051.

Hawker, G. A., Mian, S., Kendzerska, T., \& French, M. (2011). Measures of adult pain: Visual analog scale for pain (vas pain), numeric rating scale for pain (nrs pain), mcgill pain questionnaire $(\mathrm{mpq})$, short-form mcgill pain questionnaire (sf-mpq), chronic pain grade scale (cpgs), short form-36 bodily pain scale (sf-36 bps), and measure of intermittent and constant osteoarthritis pain (icoap). Arthritis Care Res, 63(11), 240-252.

Haywood, K. L., Packham, J. C., \& Jordan, K. P. (2013). Assessing fatigue in ankylosing spondylitis: The importance of frequency and severity. Rheumatology, 53(3), 552-556.

Jeong, H., Eun, Y. H., Kim, I. Y., Kim, H., Lee, J., Koh, E. M., \& Cha, H. S. (2016). Characteristics of hip involvement in patients with ankylosing spondylitis in Korea. Korean J Intern Med, 32(1), 158-164.

Karayazgan, S. (2013). Şizofreni hastalarına bakım verenlerin aktivite, aktivite performansı ve sağlıkla ilgili yaşam kalitelerinin incelenmesi. Hacettepe Üniversitesi Sağlık Bilimleri Enstitüsü. Yüksek Lisans Tezi.

Karkucak, M., Özden, G., Çapkın, E., Tosun, M., Alaca, H., \& Barçak, Ö. (2010). Ankilozan spondilitte anksiyete ve depresyon düzeyi, yaşam kalitesini etkileyen faktörler. FÜ Sağ Bil Tıp Derg, 24, 13-19.

Law, M., Baptiste, S., Carswel, A., McColl, M. A., Polatajko, H., \& Pollock, N. (2005). Canadian Occupational
Performance Measure. CAOT Publications ACE.

Lee, K. A., Hicks, G., \& Nino-Murcia, G. (1991). Validity and reliability of a scale to assess fatigue. Psychiatry Research, 36(3), 291-298.

Onen, F., Akar, S., Birlik, M., Sari, I., Khan, M. A., Gurler, O., Ergor, A., Manisali, M., \& Akkoc, N. (2008). Prevalence of ankylosing spondylitis and related spondyloarthritides in an urban area of Izmir, Turkey. J Rheumatol, 35(2), 305-9.

Price, D. D., McGrath, P. A., Rafii A., \& Buckingham, B. (1983). The validation of visual analogue scales as ratio scale measures for chronic and experimental pain. Pain, 17, 45-56.

Spadaro, A., De Luca, T., Massimiani, M. P., Ceccarelli, F., Riccieri, V., \& Valesini, G. (2008). Occupational therapy in ankylosing spondylitis: Short-term prospective study in patients treated with anti-TNF-alpha drugs. Joint Bone Spine, 75(1), 29-33.

Tyrrell, J.S., \& Redshaw, C.H. (2016). Physical activity in ankylosing spondylitis: Evaluation and analysis of an eHealth tool. J Innov Health Inform, 23(2), 169.

Ünsal, A. (2009). Evaluation of Fatigue in Individuals with Arthritis. Hacettepe University Faculty of Health Sciences Nursing Journal, 16, 1-10.

Vlieland, T. V., \& Li, L. C. (2009). Rehabilitation in rheumatoid arthritis and ankylosing spondylitis: Differences and similarities. Clin Exp Rheumatol, 27(55), 171-178.

Ward, M. M. (1999). Health-related quality of life in ankylosing spondylitis: A survey of 175 patients. Arthritis Care Res, 12(4), 247-255.

Yurtsever, S., \& Bedük, T. (2003). Hemodiyaliz hastalarında yorgunluğun değerlendirilmesi. Hemşirelikte Araştırma Geliştirme Dergisi, 2, 3-12. 